\title{
Knowledge Sharing and the Innovation Capability of Chinese Firms: The Role of Guanxi
}

\author{
Oswaldo Jose Jimenez Torres \\ School of Business Management, Harbin Institute of Technology, Harbin, China \\ E-mail: Oswaldojim@gmail.com
}

Received 20 July 2016; Accepted 10 September 2016;

Publication 30 September 2016

\begin{abstract}
Building on the theory of social capital the present theoretical study aims to introduce a framework to analyze the extent to which the innovation capability of Chinese firms is affected by Guanxi as a moderator between the former and the knowledge sharing behaviors among individuals and teams. The three dimensions of knowledge sharing considered here are: Type of knowledge, quantity and quality of knowledge shared among employees. Also this article includes propositions and recommendations to lead future research in this area.
\end{abstract}

\section{Introduction}

The set of social principles known as Guanxi (关系) is the central piece of the Chinese society, it has its origins in the Confucianism which has been part of the Chinese social system for over 2.500 years. Confucianism encloses the theory of relationalism, which states that individuals must be relationshipbased. Even though, this ancient philosophy also clearly differentiates the most important human relationships known as lun or wu lun (五伦) which can be translated as (Five Circles or Five Cardinal Relationships), and those are: ruler-subject (君臣), father-son (父子), husband-wife (夫婦), elder

Journal of Industrial Engineering and Management Science, Vol. 1, 1-18.

doi: 10.13052/jiems2446-1822.2016.001

(c) 2016 River Publishers. All rights reserved. 
brother-younger brother (兄弟), and friend-friend (朋友). In its core Confucianism have three main precepts, which are: The importance of human relationships, the social order and the pertinent moral principles that guide the behaviors of individuals [1]. Much of the literature on Guanxi is businessorientated, in that, is focused on grasp and explain to non-Chinese the relevance and complexities of this concept for conducting negotiations and achieve competitive advantage in China as well as dealing with Chinese organizations overseas. While the values of the Chinese society have evolve trough out the years it's still based on the idea of the Confucian society and so Guanxi relationships are conducted considering those values. Two core principles of Guanxi are identified in literature. The first one is the principle reciprocity or exchange of favors (renqing), this means that individuals must assist those who assisted them, and it's important to notice that this reciprocity must be balanced. The second, it's the principle of long-term equity, it means that parties of an exchange are permitted to share the outcome of the exchange giving their input on it in the long-term [2].

Different authors have studied the effects of social norms in organizations, such as [2], whom based on the theory of social capital proposed that favor exchanges among colleagues in organizations outside the private lives frequently implicate the use of organizational resources as well as positions. This practices benefit the subjects involved in this dynamics, in that, the provider increases his private social capital and the receiver coup his needs. Notwithstanding, those behaviors doesn't contribute to enhance the public social capital of the organization as a whole. [3] showed that individuals who share strong empathy with each other tent to foster this empathy by providing resources also between them, even when this implicates neglecting the collective good [4]. In the light of this, it can presumed that the behaviors implicit in Guanxi relationships, even though generate benefits for individuals whom share close ties with each other, might be detrimental for organizations, specifically for knowledge sharing practices among team members, because those would act as a barrier restricting the equalitarian or unbiased flow of knowledge between all the members involve in specific tasks for an organization and therefore holding back the innovation capability of the firm. The role of intra-organizational knowledge sharing in enhancing innovation capability of firms has been the focus of previous research for instance $[5,6]$, its importance in accelerating individuals and teams problem-solving capacity, generation of new ideas and business models is created by both knowledge donating and collecting among individuals in an organization. 
The clear distinctions established on the Confucian precepts about the kind of relationships individuals have, the obligations of the parties and the moral principles applicable in each different case suppose and unequal or discriminatory treatment of members in society or groups. Considering this, it's worthy to analyze the impact of all this socio-cultural connotations in the organizational context in order to identify whether those are beneficial, harmful or irrelevant for organizations. Therefore the main assumption of the present study is that the innovation capability of Chinese organizations is affected by the role of Guanxi as a moderator between the former and the knowledge sharing behaviors of their staff. Hence this study presents a conceptual framework built on previous literature as well as propositions and directions for upcoming research on this subject. The dimensions of knowledge sharing to be addressed are the following: Type of knowledge (explicit and tacit), quality and quantity.

\section{Literature Review}

\subsection{Guanxi and the Theory of Social Capital}

The basic notion embedded in the theory of social capital is that a person's social networks, conformed by his (friends, colleagues and other contacts) constitutes a form of capital and that individuals often times engage in activities leading to enhance their private social capital regardless of the public social capital. Therefore after observing the principles of Guanxi relationships and the behaviors of individuals whom follow those precepts distinguishing between insiders and outsiders to their social circles, academics have identified the theory of social capital as a fit kaleidoscope to analyze this social norm with due scientific rigorosity. [7] studied the concept of social capital considering the approach of two main intellectual streams focused on social action. One of those treats actors as social individuals highly influenced by a set of norms, rules as well as obligations. On the other hand, we found the economical stream of though, the basic assumption here is that the actor drives himself according only to his self-interest. [8] explained that social capital can operate in two forms depending on the actors and their dynamics, in this sense, public social capital is owned by the unit or organization as a whole while private social capital is owned only privately by a certain group of individuals. [9] defined social capital as: "The sum of the resources, actual or virtual, that accrue to an individual or a group by virtue of possessing a durable network of more or less institutionalized relationships of mutual acquaintance and recognition". 
[10] introduced a comprehensive analysis on the different definitions that had been attributed to Guanxi throughout decades, also some examples of the various meanings the word Guanxi can have depending on the context. Some definitions relevant for academia are: "Friendship with implications of a continual exchange of favors" [11]. "The concept of drawing on connections in order to secure favors in personal relatives" [12]. Other approaches taken for the study of Guanxi are [13], they focused on explain the differences between the communist based managerial system applied in China and the new one managers are engaging on nowadays which is a capitalistic social system with clear Anglo-Saxon features, for instance strong ethical values and clear rules of trade, [2] this is a conceptual article in which the authors based on the theory of social dilemma explained how the close ties implicit in Guanxi relationships generate "externalities" in groups and also explained some managerial actions that mitigate those, such as foster group identity in organizations. [14] the focus of this research was to examine indigenous forms of informal influence in different locations. The authors analyzed the concepts and dynamics of Guanxi, Wasta, Jeithinho and Svyazi, they verified that the dynamics implicit in this concepts are more frequent in places with self-enhancement values, low self-transcendence values and high impunity of corruption. [15] this work provides a much needed comparison between Guanxi and its analog in the Arab world, Wasta. Here the author explained that one of the main similarities that makes the concepts of Guanxi and Wasta to flourish in their respective societies is that those are low-context societies. [16], in that article authors studied which factors could foster knowledge sharing, the selected factors were: Trust, Guanxi orientation and face. [17], here the concept of Guanxi was operationalized, presenting the following components: Trust, relationship commitment, and communication. [18], the dynamics and importance of Guanxi are studied not also at the corporate level but also to the governmental level.

[12] focused on analyze how firms apply Guanxi, specifically the way it is used to cope with competitive and resource disadvantages. Based on their results, they explained that Guanxi relationships might benefit organizations in terms of market expansion and competitive advantage but not in internal operations. [19], this work studied the ethical dimension of Guanxi, here some of the negative features of it were presented, such as corruption and misgiving behavior. In his final remarks the author argued that in the case of international firms Guanxi it's still necessary, specially at the beginning of their operations in China, but its importance is likely to decline as companies 
start acting according to pure market strategy, finally the author anticipated the total misused of Guanxi in the feature due to China's modernization.

\subsection{Knowledge Sharing}

Previously, authors have studied knowledge sharing with the following approaches: [20] concentrated on explore the extent to which cultural factor affect knowledge sharing in virtual communities. Based on their findings, they argued that the issue of saving face in China was less relevant than expected. Hence, considering arguments of $[21,22]$ on the evolution of Guanxi, it could be presumed that this discrepancies between the verified and expected importance of saving face as an element associated with Guanxi practices might was caused by an evolution of the Guanxi itself. Also, [23] identified major barriers to knowledge sharing in China, such as modesty requirements and competitiveness. On the other hand those issues were less important in Russia and Brazil. [24] explained how personal networking and membership affects knowledge sharing also in Russia and China.

Authors also have identified two dimensions of knowledge sharing, even though each study has defined those dimensions using different concepts, in essence, those can be reduced to giving and receiving knowledge. [25] explained that the knowledge sharing process involves bringing or ("donating") knowledge and getting or ("collecting") knowledge. Moreover, [26] while focusing on the knowledge sharing dynamics in virtual communities proposed that both the demand and supply of knowledge are critical for such communities to be vibrant. Therefore, aiming to assess the knowledge sharing among employees in the presence of Guanxi, the present study proposes to analyze both dimensions of knowledge sharing under the definitions "knowledge shared" and "knowledge received", and also take this approach to addresses the other dimensions of knowledge identified in this framework.

\subsection{Innovation Capability}

Literature on innovation capabilities has covered the following topics: [27] explored the impact of intellectual capital both in incremental and radical innovation. Among their findings, they verified a positive relationship between organizational capital and radical innovative capability. On the other hand, they noticed a negative relationship between human capital and radical innovative capability. [28] confirmed the influence of certain aspects of organizational learning orientation in firm's innovative capability, specifically: commitment 
to learning, shared vision, open-mindedness, and intra-organizational knowledge sharing. [29] here the authors link inter-firm relationship strengths and tacitness of knowledge transfer, its extent and innovation capability, and also innovation capability and innovation performance, all this based on the theory of knowledge.

\subsection{Tacit Knowledge}

Authors have focused in grasp the relevance of this kind of knowledge at the organizational level. [30] this paper summarized and analyzed the most widely spread techniques used in organization to acquire, measure, teach, share and apply knowledge, also presents methods to use both tacit and explicit knowledge more effectively in organizations. [31] focused on generate ways to assess and use tacit knowledge using Polanyi's theories. The author presented the way in which intranet documents can be used to make tacit knowledge tangible without become it explicit, been this one of the reasons why people would rather not to share tacit knowledge, specifically, the three reasons for this phenomena according stated in that study are: (1) People is not conscious about the tacit knowledge they poses, (2) for people's use is not necessary to make it explicit, and (3) share tacit knowledge might represent lose competitive advantage. [32] summarized some barriers that organizations might face to transform tacit knowledge into the explicit kind, also some recommendations are presented. [33] examined the relevance of tacit knowledge for the innovation process and show how different geographical location affects the dynamics between knowledge and innovative activity, and the extent to which this interaction influences the geography of innovation and economic activity.

\subsection{Explicit Knowledge}

This kind of knowledge it's easier to transmit among individuals and groups, in fact, one of the main objectives of organizations it's to recognize tacit knowledge and transform it into explicit, or at least be able to transform as much knowledge as possible, it's important to stress this point given that compelling argumentation included in previous literature, for instance [34] basically states that tacit knowledge cannot be transform into explicit. Also, more recently $[35,36]$ argued that there are certain dimensions of knowledge that can't be reach. Opposite to tacit knowledge which is personal in nature (know-how), explicit knowledge needs to be created and neutered on the basis of tacit knowledge [37]. [38] also distinguished two categories of explicit 
knowledge, which are: object-based and rule-based. Object-based explicit knowledge is fixed into artifacts and often is presented through symbols, while rule-based explicit knowledge tent to be represented rules or organization's procedures [39].

\subsection{Knowledge Quality}

The concept of knowledge quality has been operationalized containing accuracy, timeliness, and usefulness. [40] moreover, previous literature has linked quality of knowledge with superior levels of trust. [41] explained the value of accurate information and its effects on the perception of trustworthiness, focusing on the relations between managers and employees. The author argued that workers consider their managers as trustworthy when the information they share was accurate and forthcoming, plus, clear explanations and opportune feedback when taking decisions cause superior levels of trust. [42] in this vine of research, stated that when subordinates believe that the information they received from their superiors was accurate the perception of trust increased. The authors also probed that in the cases where subordinates trust their superiors both the desire for interaction and the satisfaction with the communication raised. On the other hand, low levels of trust were linked with blocking or withholding the upward information flow. Based on those previous findings, in the present research is presumed that the lack of quality information flow also cause similar effects in horizontal relationships among colleagues, and that the externalities implicit in Guanxi might be a major factor that block or diminish significantly the stream of quality information between all the members in organizations, hence contracting innovation capability of firms.

\subsection{Knowledge Quantity}

Knowledge quantity is regarded as the perception of members in the organization that they are getting enough information [43]. Literature focused on this concept includes [44], in that paper, they explored the frequency of information been shared among managers in a multinational company, and confirmed that the perception of trustworthiness of the trusty and the trustor are closely related with the frequency of information shared between parties. [45] focused on the assumption that more communication is better for organizations, and this is defined as a "communication metamyth". Among the most salient findings of this research is that employees from all the organizations studied expressed their yearning for more information coming from different sources, this is, 
formal and informal ones. Also, this article explained that desire for more information is based on the assumption that organizational problems can be elucidated through further communication.

[46] based on the Uncertainty Reduction Theory explains how the provision of additional information among staff members benefits organizations, specifically, by reducing uncertainty levels and at the same time spurring satisfaction with the communication process. That study also explains the extent to which audits can add to better communication strategies in organizations. Therefore, acknowledging the relevance that variations in frequency or amount of knowledge flow can generate in organizations, it's worthy to analyze the extent to which Guanxi as a moderator can affect the flow of knowledge sharing among staff members, and finally the overall impact in the innovation capability of firms.

\section{Cultural Dissimilarities between China and Both Confucian and Non-Confucian Societies}

Most of the previous research on knowledge sharing behaviors and its links to innovation had been conducted in western countries, for this reason the results and even the very approaches taken to conduct those might not fit in different cultural context or countries with rather opposite economic and political models such as China, even considering the results obtained in different organizational studies in other countries in northeast Asia might not apply to the Chinese framework since the social norms embedded in those societies involve different a set of values. Japan and Korea share roots with the Chinese culture and so the Confucian precepts are also embraced in those countries, never the less some substantial variations can be acknowledged. Different authors have identified Wa as the analogous social code of Guanxi applied in Japan. Wa can be understood as harmony, and it's composed by other social values that basically aim to foster harmony and unity in the Japanese society [47]. Based on this facts and previous studies on Guanxi, in which it has been considered rather as a dyadic or close-network figure in society [1] we can identify a key difference from Wa. This Japanese social norm aims to foster a collectivistic society placing the interest of the community or organization first instead of individuals, while the main objective of Guanxi relationships is to provide benefits and advantages for individuals instead of the whole community. Therefore, it could be assumed that the relationship

between knowledge sharing behaviors and the innovation capability of the 
firms in a social context based on the values of Wa would be substantially different from results obtained in China.

Another country with strong bases in the Confucian theory is Korea, in which the philosophy of Inhwa is the cornerstone of the society arguably at the same extent that Guanxi is in China, although the concept of kibun it's very important in the Korean society as well [48]. Inhwa, is similar to the Japanese concept of Wa, in that, it foster the ideas of harmony in society, kibun can be interpreted as a set of tools to reach Inhwa. This social norm stresses the importance preserving pride, face, and a peaceful state of mind for the self as well as for others, thus Inhwa can be seen as more inclusive social norm as compare with Guanxi. For this reason, as previously mentioned in the case of Wa, the knowledge sharing behaviors of employees and its impact in the innovation capability of the firm under the set of values contained in Inhwa might present divers trends as compare with China.

The knowledge sharing behaviors and their impact in innovation capability of firms in the Chinese context it's also very likely to differ from non-Confucian-based societies. For instance, Wasta, which is an indigenous concept of Arab countries refers to a process whereby individuals can achieve goals by networking with key persons [14]. [49] Wasta relationships are often times a source of pride and prestige for the parties involved. While in China Guanxi relationships have a rather negative connotation in the society.

[14] explained that the similarities found between different social norms or indigenous influence styles across cultures does not diminish the importance of analyzing those separately in order to grasp particular organizational behaviors in those locations. Also, they argued that the breakthroughs got by studying each of those indigenous styles alone might be useful in different locations. Therefore, the results obtained in this research as well as the conclusions reached will not only be applicable in the Chinese context, but also have the potential to help researches and managers to understand the same phenomena in different cultural context.

Moreover, the impact of local cultures in knowledge sharing behaviors has been addressed in previous literature such as [50] they explained how collectivistic and individualistic cultures practice different methods to treat information and create knowledge. So it can be accepted that knowledge sharing behaviors, it's externalities as well as the solutions to those should not be analyzed using the "one-size-fits-all" approach, instead general theories of organizational behavior should be consider along with the due specific socio-cultural connotations. 


\section{Propositions}

According with the analysis of previous literature conducted for the present study as well as the approach taken for it, a series of propositions are presented next:

Proposition 1: The correlation between type of knowledge shared and the innovation capability of firms will be moderated by Guanxi such that the correlation will be significantly less strong when a high level of Guanxi is verified.

Proposition 2: The correlation between type of knowledge received and the innovation capability of firms will be moderated by Guanxi such that the correlation will be significantly less strong when a high level of Guanxi is verified.

Proposition 3: The correlation between the quality of knowledge shared and the innovation capability of firms will be moderated by Guanxi such that the correlation will be significantly less strong when a high level of Guanxi is verified.

Proposition 4: The correlation between the quality of knowledge received and the innovation capability of firms will be moderated by Guanxi such that the correlation will be significantly less strong when a high level of Guanxi is verified.

Proposition 5: The correlation between the quantity of knowledge shared and the innovation capability of firms will be moderated by Guanxi such that the correlation will be significantly less strong when a high level of Guanxi is verified.

Proposition 6: The correlation between the quantity of knowledge received and the innovation capability of firms will be moderated by Guanxi such that the correlation will be significantly less strong when a high level of Guanxi is verified.

\section{Economic Relevance}

Concrete governmental actions to spur innovation in Chinese organizations had been taken by China's central government, which in 2005 released the Medium-and Long-term National Plan for Science and Technology 


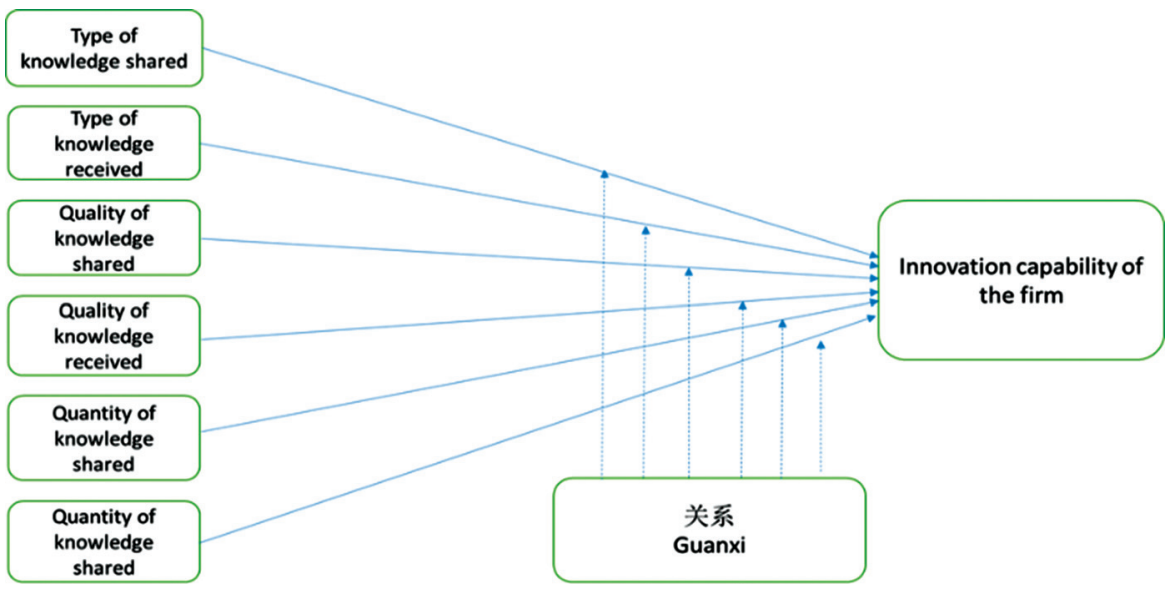

Figure 1 Diagram of the model proposed.

Development (2006-2020) [51]. It included the policy of 'indigenous innovation' as part of China's national strategy. [52] explored the evolution of the innovation process in China by identifying three stages of technology innovation: imitative innovation, cooperative innovation, and indigenous innovation. That study argued that even though China had achieve success in implementing the two previous stages of innovation (imitative and cooperative), indigenous innovation still had been elusive to Chinese organizations. Hence, the object of the present research is closely aligned with current managerial needs generated by the necessity to stimulate innovation capabilities pressing Chinese organizations.

\section{Discussion}

Both the theory of social capital and the indigenous social norm of Guanxi include precepts that stress the distinction between insiders and outsiders in relation with an individual's social circle. In this sense, we found the figures of private social capital in one hand and the relationalism embedded in Guanxi relationships in the other. By answering the main question of this research important contributions for the literature on organizational behavior could be obtained, as well as set the bases for future research. The main question to be addressed is:

Does the innovation capability of Chinese organizations is affected by the role of Guanxi as a moderator between the former and the knowledge sharing behaviors of their employees? 
The main outcomes of conducting an empirical research based on the framework here presented can be summarized as follows:

First, identify the current state of Guanxi in Chinese organizations, specifically how it moderates the relationship between knowledge sharing behaviors among employees and the innovation capability of firms. The evolutive nature of this concept has been addressed in previous literature, for instance [53, 54]. Hence, this study is focused on determine the extent to which the ongoing changes in Chinese organizations generated by diverse factors, such as the generational shifts in management positions and new societal objectives along with a strong influence from the western world affects the relevance of Guanxi and its role between knowledge sharing and the innovation capability of firms [55].

Second, find the features of the Chinese organizations that have mitigated the externalities implicit in Guanxi, previous research points to organizational aspects that can influence knowledge sharing behaviors in despite of the presence of Guanxi, such as HR practices [2], also group size has been identified as a factor that can determine the practice of knowledge sharing behaviors [56]. The empirical development of the theoretical framework here presented also could shade light on the demographics in each organization and their role in the innovation capability, some individual characteristics to focus on could be age and gender given that their role in knowledge sharing dynamics has been proved $[57,58]$. By classifying the relevant features of the organizations that have successfully reduced the externalities present in Guanxi, more organizations could consider, adapt and apply those managerial practices to deal better with indigenous social norms.

Third, present empirical bases to compare the role and evolution of Guanxi in intra-organizational knowledge sharing behaviors and innovation capabilities in Chinese organizations with the impact of analogue social norms at the organizational level in different countries, this in order to foster the design of more comprehensive and universal managerial principles.

\section{Conclusion}

To consider the particularities implicit in Guanxi at both individual and organizational level as well as verifying its role in the innovation capability of Chinese firms is a promising approach that addresses a core issue identified for China's central government and Chinese private companies. Also, comparing this Chinese social norm with analogue figures from both Confucian and non-Confucian societies as proposed in this theoretical framework would 
contribute to create more accurate managerial principals. The operationalization of the variables here presented as well as other aspects regarding methodology would be covered in a follow up work. An empirical study built on this conceptual framework could also include the analysis of second order variables that might explain different results across organizations such as: Industry, staff composition, age of the organization, etc. This would also contribute to identify more directions for new research.

\section{References}

[1] Chen, X.-P., and Chen, C. C. (2004). On the intricacies of the Chinese guanxi: a process model of Guanxi development. Asia Pac. J. Manag. 21, 305-324.

[2] Chen, C. C., and Chen, X.-P. (2008). Negative externalities of close Guanxi within organizations. Asia Pac. J. Manage. 26:3753.

[3] Batson, C. D., Batson, J. G., Todd, R. M., Brummett, B. H., Shaw, L. L., and Aldeguer, C. M. R. (1995) Empathy and the collective good: caring for one of the others in a social dilemma. J. Pers. Soc. Psychol. 68, 619-631.

[4] Chen, Y., Friedman, R., Yu, E., and Sun, F., (2009). Examining the positive and negative effects of Guanxi practices. Asia Pac. J. Manag. 28, 715-735.

[5] Liebowitz, J. (2002). Facilitating innovation through knowledge sharing: a look at the US Naval surface warfare center-cardrock division. $J$. Comput. Inform. Syst. 42.5, 1-6.

[6] Lin, H.-F. (2007). Knowledge sharing and firm innovation capability: an empirical study. Int. J. Manpow. 28, 315-332.

[7] Coleman, J. S. (1988) Social capital in the creation of human capital. Suppl. Organ. Inst. Sociol. Econ. Approaches Anal. Soc. Struct. 94, S95-S120.

[8] Van Buren, H., and Leana, C. R. (2000). "Building relational wealth through employment practices," in Relational Wealth: The Advantages of Stability in a Changing Economy, eds C. R. Leana and D. M. Rousseau (New York, NY: Oxford University Press), 233-246.

[9] Bourdieu, P., and Wacquant, L. J. D. (1992). An Invitation to Reflexive Sociology, Chicago, IL: University of Chicago Press.

[10] Wei, H., and Youmin, X. I. (2001). Is Guanxi a model of China's business? Asia Pac. Manag. Rev. 6, 295-304. 
[11] Davies, H., Leung, T. K. P., Luk Yiu-hing Wong, S. T. K. (1995). The benefits of "Guanxi" the value of relationships in developing the Chinese market. Ind. Market. Manag. 24:207-214.

[12] Park, S. H., and Luo, Y. (2001). Guanxi and organizational dynamics: organizational networking in Chinese firms. Strat. Manag. J. 22, 455-477.

[13] Berger, R., Herstein, R., and Mitki, Y. (2013). Guanxi: the evolutionary process of management in China. Int. J. Strat. Change Manag. 5.

[14] Smith, P. B. (2011). Are indigenous approaches to achieving influence in business organizations distinctive? A comparative study of Guanxi, Wasta, Jeitinho, Svyazi and pulling strings. Int. J. Hum. Resour. Manag. 23, 1-16.

[15] Hutchings, K., and Weir, D. (2006). Guanxi and Wasta: a comparison. thunderbird international business review. Thunderbird Int. Bus. Rev. 48, 141-156.

[16] Huang, Q., Davison, R. M., and Gu, J. (2011). The impact of trust, Guanxi orientation and face on the intention of Chinese employees and managers to engage in peer-to-peer tacit and explicit knowledge sharing. Inform. Syst. J. 21, 557-577.

[17] Bala Ramasamya, Gohb, K. W., and Yeung, M. C. H.(2006). Is Guanxi (relationship) a bridge to knowledge transfer? J. Bus. Res. 59, 130-139.

[18] Buckley, P. J., Clegg, J., and Tan, H. (2006). Cultural awareness in knowledge transfer to China-The role of Guanxi and mianzi. J. World Bus. 41, 275-288.

[19] Fan, Y. (2007). Guanxi, government and corporate reputation in China: Lessons for international companies. Market. Intell. Plann. 25, 499-510.

[20] Ardichvili, A., Maurer, M., Li, W., Wentling, T., and Stuedemann, R. (2006). Cultural influences on knowledge sharing through online communities of practice. J. Know. Manag. 10, 94-107.

[21] Guthrie, D. (1999). Dragon in a Three-Piece Suit: The Emergence of Capitalism in China. Princeton, NJ: Princeton University Press.

[22] Yang, M. M. (2002). The resilience of Guanxi and its new deployments: a critique of some new Guanxi scholarship. China Q. 170, 459-476.

[23] Snejina Michailova, H. K. (2004). Facilitating knowledge sharing in Russian and Chinese subsidiaries: the role of personal networks and group membership. J. Know. Manag. 8, 84-94.

[24] van den Hooff, B., and de Ridder, J. A. (2004). Knowledge sharing in context: the influence of organizational commitment, communication climate and CMC use on knowledge sharing. J. Know. Manag. 8, 117-130. 
[25] Ardichvili, A., Page, V., and Wentling, T. (2003) Motivation and barriers to participation in virtual knowledge-sharing communities of practice. $J$. Know. Manag. 7, 64-77.

[26] Subramaniam, M., and Youndt, M.A. (2005). The influence of intellectual capital on the types of innovative capability. Acad. Manage. J. 48, 450-463.

[27] Calantone, R. J., Tamer Cavusgila, S., and Zhao, Y. (2002). Learning orientation, firm innovation capability, and firm performance. Ind. Mark. Manage. 31, 515-524.

[28] Cavusgil, S. T., Calantone, R. J., and Zhao, Y. (2003). Tacit knowledge transfer and firm innovation capability. J. Bus. Ind. Mark. 18, 6-21.

[29] Smith, E. A. (2001). The role of tacit and explicit knowledge in the workplace. J. Knowl. Manage. 5, 311-321.

[30] Stenmark, D. (2001). Leveraging tacit organizational knowledge. $J$. Manage. Inform. Syst. 17, 9-24.

[31] Mahroeian, H., and Forozia, A. (2012). Challenges in managing tacit knowledge: a study on difficulties in diffusion of tacit knowledge in organizations. Int. J. Bus. Soc. Sci. 3:19.

[32] Howells, J. R. L. (2002). Tacit knowledge, innovation and economic geography. Urban Stud. 39, 871-884.

[33] Polanyi, M. (1962). Personal Knowledge: Towards a Post-Critical Philosophy. Chicago, IL: University of Chicago.

[34] Leonard, D. A., and Sensiper, S. (1998). The role of tacit knowledge in group innovation. Calif. Manage. Rev. 40, 112-132.

[35] Boisot, M. (2002). "The creation and sharing of knowledge," in The Strategic Management of Intellectual Capital and Organizational Knowledge, eds C. Choo and N. Bontis (New York, NY: Oxford University Press), 65-77.

[36] Choo, C. W. (1996). The knowing organization: how organizations use information to construct meaning, create knowledge and make decisions. Int. J. Inform. Manage. 16, 329-340.

[37] Nonaka, I., Toyama, R., and Byosière, P. (2001). "A theory of organizational knowledge creation: understanding the dynamic process of creating knowledge," in Handbook of Organizational Learning and Knowledge, eds M. Dierkes, A. Berthoin Antal, J. Child, and I. Nonaka (New York, NY: Oxford University Press), 491-516.

[38] Choo, C. W., and Bontis, N. (2002). The Strategic Management of Intellectual Capital and Organizational Knowledge. Oxford: Oxford University Press. 
[39] Thomas, G. F., Zolin, R., and Hartman, J. L. (2009). The central role of communication in developing trust. J. Bus. Commun. 46, 287-310.

[40] Whitener, E. M., Brodt, S. E., Audrey Korsgaard, M., and Werner, J. M. (1998). Managers as initiators of trust: an exchange relationship framework for understanding managerial trustworthy behavior. Acad. Manage. Rev. 23, 513-530.

[41] Roberts, K. H., and O'really, C. A. (1974). Failures in upward communication in organizations: three possible culprits. Acad. Manage. J. 17, 205-215.

[42] Becerra, M., and Gupta, A. K. (2003). Perceived trustworthiness within the organization: the moderating impact of communication frequency on trustor and trustee effects. Organ. Sci. 14, 32-44.

[43] Haas, J. W., Sypher, B. D., and Zimmermann, S. (1996). Acommunication metamyth in the workplace: the assumption that more is better. Int. J. Bus. Commun. 33, 185-204.

[44] Hargie, O., Tourish, D., and Wilson, N. (2002). Communication audits and the effects of increased information: a follow-up study. J. Bus. Commun. 39:414-436.

[45] Alston, J. P. (1989). Wa, guanxi, and inhwa: managerial principles in Japan, China, and Korea. Bus. Horiz. 32, 26-31.

[46] Barnett, A., Yandle, B., and Naufal, G. (2013). Regulation, Trust, and Cronyism in Middle Eastern Societies: The Simple Economics of 'Wasta.' Leibniz Information Centre for Economics, Discussion Paper No. 7201. Available at: http://ssrn.com/abstract=2219126

[47] Bhagat, R. S., Kedia, B. L., Harveston, P. D., and Triandis, H. C. (2002). Cultural variations in the cross-border transfer of organizational knowledge: an integrative network. Acad. Manage. Rev. 27, 204-221.

[48] Medium- and long-term national plan for science and technology development (2006-2020). 国家中长期科学和技术发展规划纲要 (2006-2020 年). Available at: http://www.gov.cn/gongbao/content/2006/ content_240244.htm

[49] Ru, P., Zhi, Q., Zhang, F., Zhong, X., Li, J., and Su, J. (2012). Behind the development of technology: the transition of innovation modes in China's wind turbine manufacturing industry. Energy Policy 43, 58-69.

[50] Guthrie, D. (1999). Dragon in a Three-Piece Suit: The Emergence of Capitalism in China. Princeton, NJ: Princeton University Press.

[51] Yang, M. M.-H. (2002). The Resilience of guanxi and its new deployments: a critique of some new guanxi scholarship. China $Q$. 170, 459-476. 
[52] Berger, R., Herstein, R., and Mitki, Y. (2013). Guanxi: the evolutionary process of management in China. Int. J. Strateg. Change Manage. 5, $30-40$.

[53] Chase, R. (1998). The people factor. People Manage. 4:38.

[54] Sveiby, K.-E. (2003). Personal Conversation. Brisbane, QLD: Griffith Business School.

[55] Sawng, Y. W., Kim, S. H., and Han, H.-S. (2006). R\&D group characteristics and knowledge management activities: a comparison between ventures and large firms.

[56] Int. J. Technol. Manage. 35, 241-261.

\section{Biography}

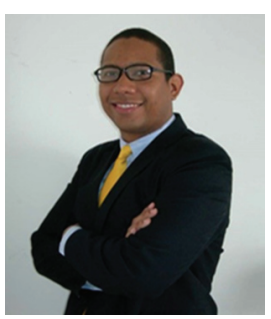

O. J. J. Torres is a senior Ph.D. candidate at the School of Management in Harbin Institute of Technology, in Harbin, PRC. His research is focused on the study and enhancement of the innovation capabilities of Chinese firms in the IT industry. He received an MBA degree from Beihua University in Jilin, China in 2012. In 2008 he earned his B.A. from Santa Maria University in Caracas, Venezuela. 
